\title{
Occupational class differences in suicide: evidence of changes over time and during the global financial crisis in Australia
}

\author{
Alison J. Milner ${ }^{1,2^{*}}$, Heather Niven ${ }^{1}$ and Anthony D. LaMontagne ${ }^{1,2}$
}

\begin{abstract}
Background: Previous research showed an increase in Australian suicide rates during the Global Financial Crisis (GFC). There has been no research investigating whether suicide rates by occupational class changed during the GFC. The aim of this study was to investigate whether the GFC-associated increase in suicide rates in employed Australians may have masked changes by occupational class.
\end{abstract}

Methods: Negative binomial regression models were used to investigate Rate Ratios (RRs) in suicide by occupational class. Years of the GFC $(2007,2008,2009)$ were compared to the baseline years 2001-2006.

Results: There were widening disparities between a number of the lower class occupations and the highest class occupations during the years 2007, 2008, and 2009 for males, but less evidence of differences for females.

Conclusions: Occupational disparities in suicide rates widened over the GFC period. There is a need for programs to be responsive to economic downturns, and to prioritise the occupational groups most affected.

Keywords: Occupation, Suicide, Recession, Gender, Socio-economic gradient, Skill level, Intentional self-harm, Gender

\section{Background}

There is long-standing interest in the influence of macroeconomic changes on population-level suicide rates [1], most recently in relation to the Global Financial Crisis (GFC) [2-7], which occurred over the period 2007 to 2010 in high-income countries. Changes during economic downturns can be explained in part by rising unemployment, and the increased risk of suicide among the unemployed. However, shifts in the working population must also be considered in order to gain a full understanding of the impact of economic downturns on suicide rates, particularly as absolute numbers of suicides among the employed exceed those among the unemployed (despite the higher rates associated with unemployment) [7]. Macro-economic changes could also affect disparities or

\footnotetext{
* Correspondence: Allison.milner@deakin.edu.au

${ }^{1}$ Work, Health, \& Welbeing Unit, Population Health Strategic Research Centre, School of Health \& Social Development, Deakin University, Building BC3.213, Burwood, Melbourne, VIC 3125, Australia

${ }^{2}$ McCaughey VicHealth Centre for Community Wellbeing, Melbourne School of Population and Global Health, University of Melbourne, Melbourne, VIC, Australia
}

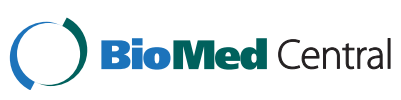

(c) 2015 Milner et al. Open Access This article is distributed under the terms of the Creative Commons Attribution 4.0 International License (http://creativecommons.org/licenses/by/4.0/), which permits unrestricted use, distribution, and reproduction in any medium, provided you give appropriate credit to the original author(s) and the source, provide a link to the Creative Commons license, and indicate if changes were made. The Creative Commons Public Domain Dedication waiver (http://creativecommons.org/publicdomain/zero/1.0/) applies to the data made available in this article, unless otherwise stated.

inequalities in rates $[8,9]$. For example, in the UK there were differential increases in suicide among those in manual occupations in the past thirty years compared to those in higher skilled jobs [10]. We recently conducted a study of all suicides in Australia over 2001-2010, showing a small and transient increase in suicide risk during the GFC period in the working population alongside a larger increase among the unemployed and economicallyinactive population [7]. In the present study, we extend this work to investigate whether the small increase in suicide rates among the employed may have masked larger changes in disparities by occupational class in Australia over the 2007-2009 GFC period compared to 2001-2006. We also assessed whether gender modified the association between the GFC and suicide. We hypothesised that males would be more affected by the GFC than females. The rationale for this was based on past research demonstrating that male suicide increased in response to labour market changes (e.g., unemployment) while female suicide did not [1]. 


\section{Method}

\section{Study design}

This retrospective mortality study consisted of a timetrend analysis of suicide rates by occupational class and gender.

\section{Data sources}

The National Coroners Information System (NCIS) is a comprehensive national internet-based data system for Australian coronial cases, established in 2001. NCIS is utilised by coroners, government agencies, and researchers for identifying cases for death investigation and research, and to monitor external causes of death in Australia. Each case on NCIS routinely includes demographic factors (age, sex, employment status, and occupation where applicable), a police description of the circumstances and background of each individual case, as well as coronial findings, autopsy and toxicology reports. Data is available for a fee and after the project has received approval from the Justice Human Research Ethics Committee (JHREC).

Population data by occupational group was obtained from the Australian Bureau of Statistics for the two census periods in 2001 and 2006. This data was coded according to the Australian and New Zealand Standard Classification of Occupations (ANZSCO) [11] by 10-year age groups (15-24 years, 25-34 years, 35-44 years, 45-54 years, 5564 years, $65-74$ years) and gender.

\section{Occupational coding}

Available information on occupation for suicide cases was coded by two researchers using the Australian and New Zealand Standard Classification of Occupations (ANZSCO) classification [11]. To be included in this study, suicide cases had to be employed at the time of death, and be of working age (15-64 years). Of the total number of eligible 8929 employed suicide cases available in the NCIS data over the period 2001-2010, 64 cases (less than $1 \%$ ) were not able to be coded due to unclear information on occupation, leaving a total of 8865 suicide cases. The analysis in this paper focuses on the first digit level of ANZSCO (the broadest classification), which represents occupational class and skill specialisation [11] across eight major groups (in the order from highest to lowest skill): $1=$ managers, $2=$ professionals, $3=$ technicians and trades workers, $4=$ community and personal service workers, $5=$ clerical and administrative workers, $6=$ sales workers, $7=$ machinery operators and drivers, and $8=$ labourers. We analysed Farmers and Farm Managers (a subgroup within ANZSCO group 1 managers) separately as this group was hard to classify into any one single group (e.g., the term 'farmer' in a case file could describe either a farm manager or farm labourer). More detailed information on the procedure for coding occupation, including a description of the eight major ANZSCO occupational groups, can be seen in Additional file 1.

\section{Suicide rate calculation}

Male and female suicide rates per 100,000 persons were calculated by broad occupational category using the 2001 and 2006 population census data by ANZSCO groupings. Rates were age-standardised using the Australian standard population (2001) [12].

\section{Analysis}

Negative binomial regression models were used to investigate Rate Ratios (RRs) in suicide by the ANZSCO major groupings, with the highest class group (Managers) as the reference. Negative binomial was chosen over Poisson regression following the identification of over-dispersion in the regression models. The GFC years $(2007,2008,2009)$ were analysed separately compared to the baseline years 2001-2006 (as one group); 2010 was also included to assess possible post-GFC related changes in suicide. The regression model controlled for age (15-24 years, 25-34 years, 35-44 years, $45-54$ years, 55-64 years) and gender (female, male). Variations between ANZSCO occupational groupings and the GFC period, and between ANZSCO occupational groupings and gender were tested by including interaction terms in a regression model. This regression model was compared against a model with no interaction terms. The significance of the interaction tests was assessed using both the likelihood ratio test (LRT) and by examining the significance of interaction terms in the model. If results were significant, negative binomial regression models were stratified by pre-GFC period (2001-2006) compared to GFC years $(2007,2008$, 2009), and 2010 (post-GFC). Coefficients were transformed into Rate-Ratios (RRs) to aid interpretation.

\section{Data access, responsibility, and analysis}

AM and HN had full access to all the data in the study and takes responsibility for the integrity of the data and the accuracy of the data analysis.

\section{Ethics committee approval}

Ethics approval for this study was grated by the Victorian Department of Justice Human Research Ethics Committee and the Melbourne School of Population and Global Health Human Ethics Advisory Group.

\section{Results}

Table 1 describes the number of suicides for males and females in each occupational group and the corresponding age-standardised suicide rates for the entire 2001 to 2010 period. For males, the highest suicide rates were among labourers, farmers, machinery operators, and technical and trade workers. For females, the 
Table 1 Total number of suicides, average population size, and age-adjusted suicide rates per 100,000 persons, over the period 2001 to 2010, males and females, Australia

\begin{tabular}{llrcc}
\hline $\begin{array}{l}\text { ANZSCO major } \\
\text { grouping }\end{array}$ & $\begin{array}{l}\text { Suicides } \\
\text { (total) }\end{array}$ & $\begin{array}{l}\text { Population size } \\
\text { (average) }\end{array}$ & $\begin{array}{l}\text { Age adjusted } \\
\text { suicide rates } \\
\text { per 100,000 }\end{array}$ \\
\hline Males & Managers & 335 & 488,908 & 7.73 \\
& Professionals & 911 & 776,735 & 13.29 \\
Tech/trade & 2,387 & $1,081,134$ & 21.12 \\
Comm Service & 459 & 275,976 & 17.2 \\
Clerical admin & 295 & $3,170,080$ & 5.26 \\
Sales & 361 & 376,916 & 13.59 \\
Machinery & 985 & 559,941 & 20.83 \\
Labourers & 1,536 & 562,885 & 34.6 \\
Farmers & 236 & 130,679 & 19.03 \\
Memales & 60 & 254,981 & 2.72 \\
Managers & 382 & 846,019 & 5.12 \\
Professionals & 117 & 173,422 & 3.64 \\
Tech/trade & 237 & 510,282 & 3.7 \\
Comm Service & 258 & $9,888,775$ & 1.39 \\
Clerical admin & 135 & 545,130 & 2.94 \\
Sales & 20 & 77,776 & 2.92 \\
Machinery & 133 & 316,143 & 5.24 \\
Labourers & 18 & 56,133 & 3.31 \\
Farmers & & & \\
\hline
\end{tabular}

highest suicide rates were in farmers, machinery operators, labourers and professionals. As can be seen in the population data, male dominated occupational groupings included technical and trade workers, professionals, machine operators, and labourers. There were a greater number of females employed in the professional worker category, sales, community service and in clerical/administrative groupings.

The main effects model with the interaction can be seen in Table 2. This suggests that males had 4-fold higher RR than females for the entire 10-years of data available. Compared to the suicide rate in managers, labourers, those employed in technical and trades, farmers and machine operators had particularly elevated RRs of suicide. The interaction tests indicated significant differences in the relationship between occupation and suicide by sex $($ LRT $x 2(8)=211.56, p<0.001)$.

Results of the interaction test examining variation in RRs in the ANZSCO occupational groupings (with managers as the reference group) by time period (i.e. GFC years 2007, 2008, 2009 versus pre-GFC period 2001-2006) and by sex, were also significant (LRT $x 2(40)=162.12, p<0.001)$. This suggests that the differences in RRs of lower skilled occupations compared to higher skilled varied over the GFC period compared to
pre-GFC, and that this relationship differed for males and females. Based on these results, models were stratified by time period and by sex. Figure 1 shows the stratified results for males (these results are also available in Additional file 2). The horizontal line marked in bold represents suicide among managers, which is the reference category for each occupational group. For males, the ratio of suicide in managers (the reference category) to professionals, technical and trade workers, community service workers, sales workers, machinery operators, labourers and farmers increased during the GFC and remained high in the year 2010 (the rate in farmers decreased but remained above managers in 2010). The rate of suicide in managers dropped slightly over the period from 5.83 per 100,000 to 2.20 per 100,000 (see footnote at the bottom of Fig. 1).

There was also a three-fold increase in the disparity of suicide rates in technical and trade workers and community service workers. Compared to managers, the RR among technical and trade workers in 2001-2006 (RR $1.87,95 \%$ CI 1.56 to $2.24, p<0.001$ ) rose to 4.25 (95\% CI 2.84 to $6.35, p<0.001)$ in 2008 and continued to increase into the year 2010 (RR 5.20, 95 \% CI 3.41 to 7.92, $p<0.001)$. Community service workers had an RR of 1.45 (95\% CI 1.17, 1.79, $p=0.001$ ) compared to managers pre-GFC. This RR increased to 3.85 in 2007 (95\% CI 2.39 to $6.19, p<0.001$ ) and continued to increase into 2010 (RR 4.17, 95 \% CI 2.51 to 6.92, $p<0.001$ ). Although not being significantly higher, the 2001-2006 RR for male labourers compared to managers nearly doubled during 2008 (RR 6.12; $95 \%$ CI 4.06 to $9.22, p<0.001$ ) and 2009 (RR 5.91; $95 \%$ CI 3.76 to 9.32, $p<0.001$ ), with only a slight decline in 2010 (RR 5.70; $95 \%$ CI 3.68 to $8.82, p<0.001)$.

Figure 2 shows stratified results for females (see Additional file 3 for results in tabular format) and the rate of suicide in managers, which dropped from 2.11 per 100,000 to 1.11 per 100,000 . Due to a low count of suicides in some occupational groups, a number of estimates were unstable which hinders interpretation of results. There was no significant elevation for technical and trade workers compared to managers during the pre-GFC period of 2001-2006. However, there was a four-fold increase in suicide among technical and trade workers compared to managers in 2007 (RR 4.33, $95 \%$ CI $1.71,10.98, p=0.002$ ) and 2008 (RR 4.01, $95 \% \mathrm{CI}$ $1.42,11.35, p=0.009)$ and a non-significant decline in 2009 and 2010. There was also an increase among females employed as machinery workers compared to managers during the GFC. The RR was 1.67 in 20012006 (95 \% CI 0.88, 3.19, $p=0.120$ ) and increased to 4.90 in 2009 (95\% CI 1.02, 23.52, $p=0.047$ ). The RRs for technical and trade workers and machine operators declined in 2010. 
Table 2 The main model and model with interaction terms, rate ratios with $95 \%$ confidence intervals comparing major occupational groups to the suicide rate in managers (the highest class group), 2001 to 2010

\begin{tabular}{|c|c|c|c|c|c|c|}
\hline & Main effec & & & Interaction & & \\
\hline & RR & $95 \% \mathrm{Cl}$ & $p$ value & RR & $95 \% \mathrm{Cl}$ & $p$ value \\
\hline Managers & Reference & & & Reference & & \\
\hline Professionals & 174 & $1.50,2.01$ & $<0.001$ & 1.37 & $1.02,1.84$ & 0.035 \\
\hline Tech/trade & 2.30 & $1.99,2.66$ & $<0.001$ & 1.14 & $0.82,1.59$ & 0.433 \\
\hline Comm service & 1.80 & $1.54,2.10$ & $<0.001$ & 1.03 & $0.76,1.40$ & 0.867 \\
\hline Clerical admin & 1.25 & $1.06,1.46$ & 0.007 & 0.81 & $0.60,1.09$ & 0.159 \\
\hline Sales & 1.62 & $1.38,1.90$ & $<0.001$ & 0.92 & $0.67,1.23$ & 0.634 \\
\hline Machinery & 2.27 & $1.94,2.65$ & $<0.001$ & 2.07 & $1.22,3.51$ & 0.007 \\
\hline Labourers & 3.62 & $3.13,4.19$ & $<0.001$ & 1.60 & $1.15,2.21$ & 0.005 \\
\hline Farmers & 2.55 & $2.11,3.08$ & $<0.001$ & 2.32 & $1.34,4.00$ & 0.003 \\
\hline Year & 0.96 & $0.90,1.11$ & 0.145 & 0.95 & $0.89,1.01$ & 0.076 \\
\hline Female & Reference & & & Reference & & \\
\hline Male & 3.87 & $3.58,4.17$ & $<0.001$ & 2.19 & $1.62,2.94$ & $<0.001$ \\
\hline $15-24$ years & Reference & & & Reference & & \\
\hline 25-34 years & 1.60 & $1.44,1.77$ & $<0.001$ & 1.59 & $1.43,1.76$ & $<0.001$ \\
\hline $35-44$ years & 1.63 & $1.47,1.80$ & $<0.001$ & 1.64 & $1.48,1.81$ & $<0.001$ \\
\hline $45-54$ years & 1.53 & $1.38,1.70$ & $<0.001$ & 1.55 & $1.40,1.71$ & $<0.001$ \\
\hline 55-64 years & 1.29 & $1.15,1.45$ & $<0.001$ & 1.29 & $1.16,1.45$ & $<0.001$ \\
\hline Managers*Females & & & & Reference & & \\
\hline Prof*Males & & & & 1.22 & $0.88,1.71$ & 0.237 \\
\hline Tech/trade*Males & & & & 2.31 & $1.61,3.33$ & $<0.001$ \\
\hline Comm Service*Males & & & & 2.05 & $1.45,2.91$ & $<0.001$ \\
\hline Clerical admin*Males & & & & 1.67 & $1.17,2.37$ & 0.581 \\
\hline Sales*Males & & & & 2.02 & $1.40,2.92$ & $<0.001$ \\
\hline Machinery*Males & & & & 1.20 & $0.69,2.07$ & 0.523 \\
\hline Labourers*Males & & & & 2.73 & $1.90,3.90$ & $<0.001$ \\
\hline Farmers*Males & & & & 1.18 & $0.66,2.10$ & 0.581 \\
\hline
\end{tabular}

Notes: 95 \% Cls 95 \% Confidence intervals (lower, upper); $R R$ rate ratios; $p$ value = significance value $95 \%$

\section{Discussion}

\section{Main findings}

Over the period 2001 to 2010, major occupational groups with the highest rates of suicide in Australia were labourers, farmers, machine operators and technical and trade workers. There was some evidence of gender differences in rates of suicide, although both males and females had higher rates in labouring jobs. The global financial crisis was associated with increasing class disparities in suicide rates. This was most apparent among males in manual occupations.

\section{Occupational groups at risk of suicide over the period 2001 to 2010}

A number of studies have documented an elevated risk of suicide among unskilled labouring workers [7, 8, 10, 13-15]. Higher suicide rates among females and males employed in these occupations have been attributed to a range of factors including socio-economic disadvantage [10] and exposure to stressful working conditions such as low job control and high demands [7]. The results of the present study also suggest that males generally had higher suicide rates in occupations involving physical work, including labouring, agriculture, machine operators, and technical and trades employment. This finding aligns with past research on suicide among males employed in the construction $[16,17]$ and agricultural industries [9]. For females, an elevated rate of suicide was found for the professional occupational group (ANZSCO group 2), which includes doctors and other medical professionals such as nurses. Suicide among those employed in medical jobs has been attributed to greater access to means (prescription medications), job pressures, and underlying psychological vulnerabilities and mental health issues 


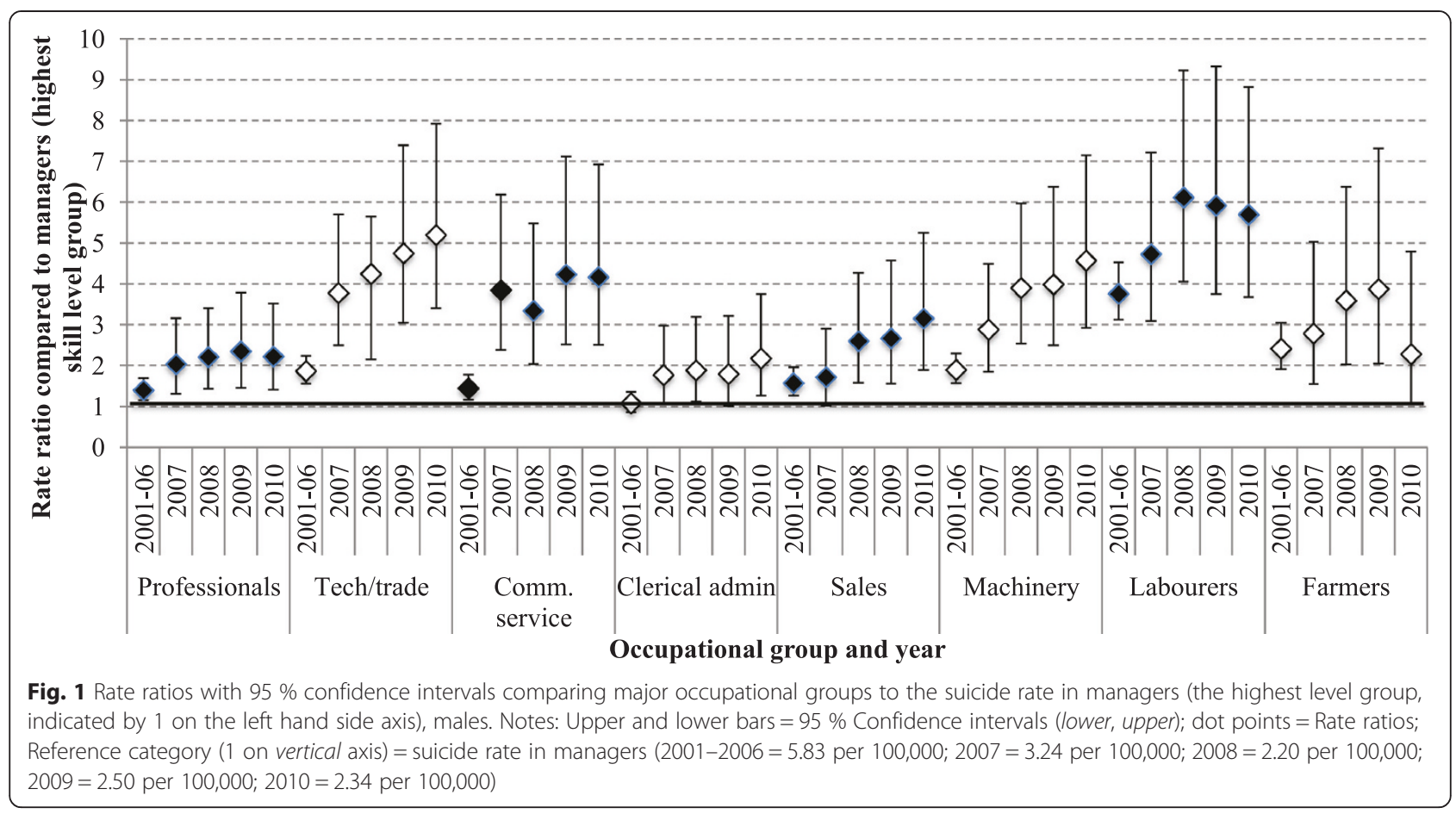

$[18,19]$. It may be that these risk factors affect females more than males, leading to their higher suicide rate. However, we should also note small sample size for females and the decreasing rate of suicide among managers. This reflects a general downward trend in the overall national suicide rates over this period, further emphasising the difference from other occupational groups. There were a number of other differences between male and female suicide over time, such as the declining rate of suicide among females in technical and trades occupations, while their male counterparts had increasing suicide. However, the small number of

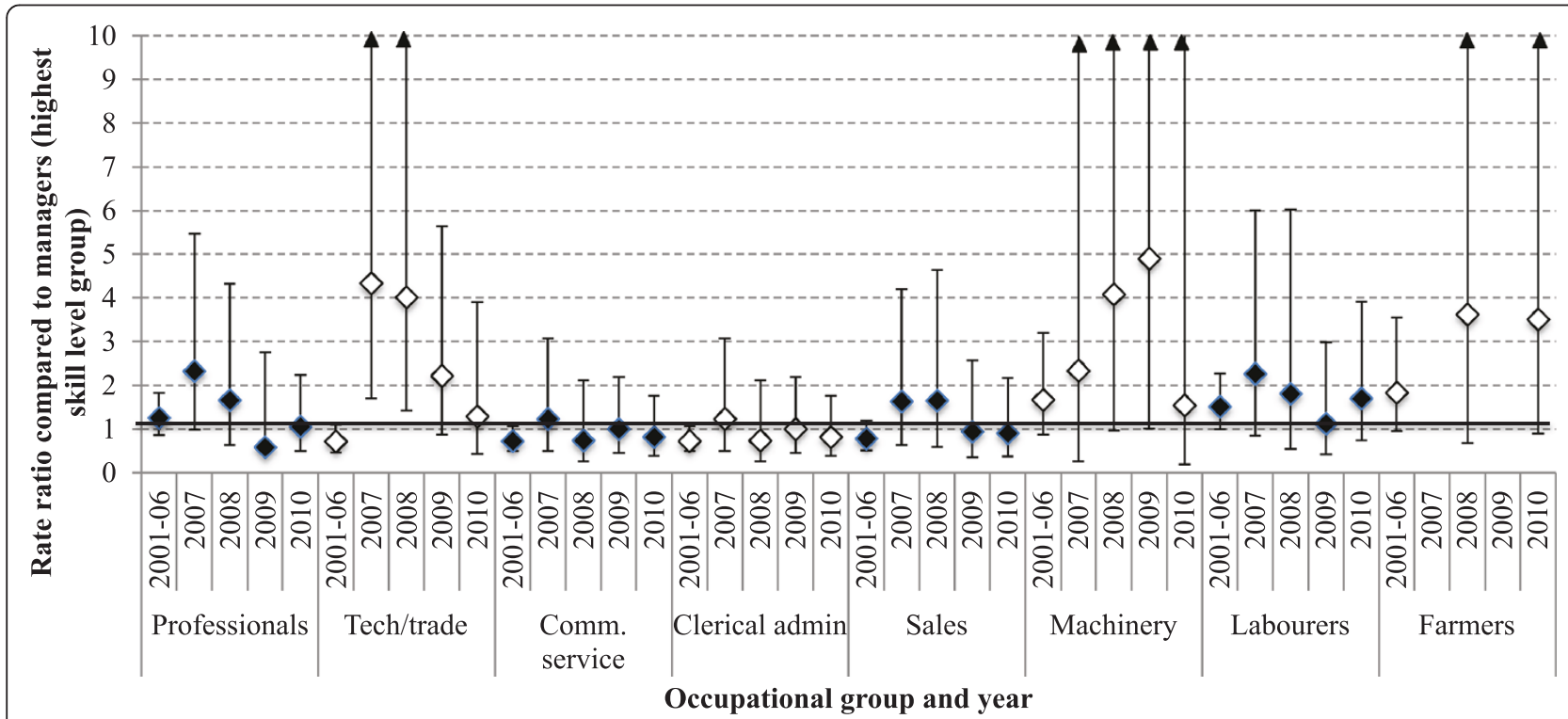

Fig. 2 Rate ratios with $95 \%$ confidence intervals comparing major occupational groups to the suicide rate in managers (the highest level group, indicated by 1 on the left hand side axis), females. Notes: Upper and lower bars $=95 \%$ Confidence intervals (lower, upper); dot points = Rate ratios; Reference category ( 1 on vertical axis) = suicide rate in managers. The arrows on tech/trade represent $95 \%$ upper Cls that are larger than 10. $(2001-2006=2.11$ per 100,000; $2007=1.11$ per 100,000; $2008=1.23$ per 100,000; $2009=1.69$ per 100,000; $2010=1.21$ per 100,000) 
suicides occurring in females means that these results were unreliable. This highlights the need for greater need for research into gender difference in suicide by occupation. We would suggest a qualitative approach to this topic may be most informative in unpacking these relationships.

\section{The association between the GFC and disparities in suicide rate by occupational class}

The GFC in Australia coincided with a widening of disparities in suicide rates by occupational class, particularly among males. Suicide rates in unskilled workers such as labourers increased from three to six-fold greater than the rates in the highest class group, while there was over a four-fold increase among technical and trade workers. Disparities persisted into the year 2010, which suggests that higher rates among unskilled labourers, and technical and trade workers, was a continuing problem. These findings correspond with research from Korea regarding the economic recession in the late 1990s, which produced persistent and widening differences in depression, suicide ideation and suicide attempts [19]. The Korean study found that the lowest income group was consistently disadvantaged compared to higher income groups [19]. Similarly, a study on suicide in the construction industry in Australia found that labourers had significantly elevated rates during the GFC compared to higher skilled occupations [17].

There are a number of potential explanations for widening occupational disparities in suicide rates. First of all, this may be connected to increasing social disparities and economic disadvantages experienced during the GFC $[10,20,21]$. It may also be related to changes in social and economic welfare policies $[2,5,21]$ and rising job insecurity [22], and more precarious employment, each of which would be more likely to affect those in lower skilled jobs. Certainly, there is evidence to suggest that lower skilled workers report greater job insecurity more than higher skilled workers [22] and that job insecurity rose in Australia during 2008 with the onset of the GFC [23]. Although there is a lack of research specifically on suicide, job insecurity predicts common mental disorders [24]. Further, lower skilled workers experience considerably higher unemployment rates than many other occupational groups in Australia [25]. In fact, the number of labourers who became unemployed in 2013 were over three times the number of unemployed in managerial or professional occupations [26]. Hence, lower skilled workers may be disproportionally concerned about their future employment prospects (even while in paid work). Another possible explanation is shifting of persons in higher class jobs into lower class jobs (demotion).

\section{Limitations}

The limitations of this study include under-reporting of suicide. This was particularly problematic in the initial years during which NCIS was established [27, 28] but may be an ongoing problem. Other possible problems include the miscoding of occupation, which may have occurred despite independent coding by two researchers and the use of a structured approach to the classification. We also acknowledge that we have used a rather crude measure of the GFC. The enormity of global events such as the most recent economic downturn means that different groups of people may have been vulnerable at different times and that the duration and intensity of the GFC could have varied by occupational group [29]. Our "before/after" year measure would have been unable to distinguish these differences. Further, small numbers of suicides in some occupational groups meant that we were unable to assess statistical significance. Notwithstanding these issues, this study has a number of strengths, including its use of the best available quality population-level data on suicide, and coverage across an entire national population over a ten year period.

\section{Conclusion}

This paper demonstrated that occupational disparities in suicide rates are dynamic over time, and can be exacerbated by economic downturns such as the 2007-2009 GFC. Further, the cessation of the GFC by 2010 was not associated with a marked reduction in rates of suicide in many occupational groups, which could indicate lasting impacts. From a suicide prevention perspective, a wide range of policy interventions from the individual support program to macro-economic policy levels should be considered, tailored in particular to the occupational groups most at risk of suicide during economic downturns.

\section{Additional files}

\section{Additional file 1: Information on the coding of occupation. (DOC $25 \mathrm{~kb}$ ) \\ Additional file 2: Rate ratios with $95 \%$ confidence intervals comparing major occupational groups to the suicide rate in managers (the highest skill level group), males. (DOC $40 \mathrm{~kb}$ ) \\ Additional file 3: Rate ratios with $95 \%$ confidence intervals comparing major occupational groups to the suicide rate in managers (the highest skill level group), females. (DOC $44 \mathrm{~kb}$ )}

\section{Abbreviations}

ANZSCO: Australian and New Zealand Standard Classification of Occupations; GFC: Global financial crisis; RR: Rate ratios; JHREC: Justice Human Research Ethics Committee; NCIS: National Coroners Information System.

\section{Competing interests}

The authors declare that they have no competing interests. 


\section{Authors' contributions}

AM conceived the article, conducted coding and analysis, and wrote the initial draft. HN contributed to data extraction and coding. ADL and HN contributed to the drafts of the manuscript. ADL contributed to interpretations of results. All authors made substantial contributions to the final draft. All authors read and approved the final manuscript.

\section{Acknowledgements}

This work was supported by Australian National Health and Medical Research Council Capacity Building Grant in Population Health and Health Services Research (ID: 546248) and a Centre grant from the Victorian Health Promotion Foundation (Melbourne). The funding source had no involvement in the study design; collection, analysis and interpretation data; the writing of the report; or in the decision to submit the paper for publication.

Received: 14 March 2015 Accepted: 11 September 2015

Published online: 21 September 2015

\section{References}

1. Berk M, Dodd S, Henry M. The effect of macroeconomic variables on suicide. Psychol Med. 2006;36:181-9.

2. Barr B, Taylor-Robinson D, Scott-Samuel A, McKee M, Stuckler D. Suicides associated with the 2008-10 economic recession in England: time trend analysis. BMJ. 2012;345:e5142.

3. Chang S-S, Stuckler D, Yip P, Gunnell D. Impact of 2008 global economic crisis on suicide: time trend study in 54 countries. BMJ. 2013;347: http://dx.doi.org/10.1136/bmj.f5239.

4. Reeves A, Stuckler D, McKee M, Gunnell D, Chang S-S, Basu S. Increase in state suicide rates in the USA during economic recession. Lancet. 2012;380:1813-4

5. Stuckler D, Basu S, Suhrcke M, Coutts A, Mckee M. Effects of the 2008 recession on health: a first look at European data. Lancet. 2011;378:124-5.

6. Saurina C, Bragulat B, Saez M, Lopez-Casasnovas G. A conditional model for estimating the increase in suicides associated with the 2008-2010 economic recession in England. J Epidemiol Community Health. 2013;67:779-87.

7. Milner A, Morrell S, LaMontagne AD. Economically inactive, unemployed and employed suicides in Australia by age and sex over a 10-year period: what was the impact of the 2007 economic recession? Int J Epidemiol. 2014; doi:10.1093/ije/dyu148.

8. Milner A, Spittal MJ, Pirkis J, LaMontagne AD. Suicide by occupation: a systematic review and meta-analysis. Br J Psychiatry. 2013;203:409-16.

9. Kim MD, Hong SC, Lee SY, Kwak YS, Lee Cl, Hwang SW, et al. Suicide risk in relation to social class: a national register-based study of adult suicides in Korea, 1999-2001. The Int J Soc Psychiatry. 2006;52:138-51.

10. Roberts SE, Jaremin B, Lloyd K. High-risk occupations for suicide. Psychol Med. 2012;1-10 doi:10.1017/s0033291712002024

11. ABS. ANZSCO - Australian and New Zealand standard classification of occupations, First Edition, Revision 1. Cat. No. 1220.0. Canberra Australian Bureau of Statistics, 2009.

12. ABS. Australian demographic statistics, September quarter 2002. Cat. No. 3101.0. Canberra: Australian Bureau of Statistics, 2003.

13. Agerbo E, Mortensen PB, Qin P, Westergaard-Nielsen N. Risk of suicide in relation to income level in people admitted to hospital with mental illness: nested case-control study. BMJ. 2001;332:334-5.

14. Meltzer $H$, Griffiths $C$, Brock A, Rooney C, Jenkins R. Patterns of suicide by occupation in England and Wales: 2001-2005. Br J Psychiatry. 2008;193:73-6.

15. Mustard CA, Bielecky A, Etches J, Wilkins R, Tjepkema M, Amick BC, et al. Suicide mortality by occupation in Canada, 1991-2001. Can J Psychiatry. 2010:55:369-76.

16. Heller TS, Hawgood JL, Leo DD. Correlates of suicide in building industry workers. Arch Suicide Res. 2007;11:105-17.

17. Milner A, Niven $H$, LaMontagne AD. Suicide by occupational skill level in the Australian construction industry: Data from a national register of deaths over the period 2001 to 2010. Aust N Z J Public Health. 2007:38:281-5.

18. Hawton K, Malmberg A, Simkin S. Suicide in doctors. A psychological autopsy study. J Psychosom Res. 2004:57:1-4.

19. Hong J, Knapp M, McGuire A. Income-related inequalities in the prevalence of depression and suicidal behaviour: a 10-year trend following economic crisis. World Psychiatry. 2011;10:40-4.
20. Blakely T, Tobias M, Atkinson J. Inequalities in mortality during and after restructuring of the New Zealand economy: repeated cohort studies. BMJ. 2008;336:371-5.

21. Mackenbach JP, Bos V, Andersen O, Cardano M, Costa G, Harding S, et al. Widening socioeconomic inequalities in mortality in six Western European countries. Int J Epidemiol. 2003:32:830-7.

22. Astell-Burt T, Feng X. Health and the 2008 economic recession: evidence from the United Kingdom. PLoS One. 2013;8:e56674. doi:10.1371/journal. pone.0056674

23. LaMontagne AD, Krnjacki L, Kavanagh AM, Bentley R. Psychosocial working conditions in a representative sample of working Australians 2001-2008: an analysis of changes in inequalities over time. Occup Environ Med. 2013;70:639-47.

24. Stansfeld S, Candy B. Psychosocial work environment and mental health-a meta-analytic review. Scand J Work Environ Health. 2006:32:443-62.

25. Oesch D. What explains high unemployment among low-skilled workers? Evidence from 21 OECD countries. European Journal of Industrial Relations. 2010;16:39-55.

26. ABS. Labour force, Australia, detailed, quarterly, May 2013. Cat. No. 6291.0.55.003. Canberra Australian Bureau of Statistics, 2013.

27. De Leo D, Dudley MJ, Aebersold CJ, Mendoza JA, Barnes MA, Harrison JE et al. Achieving standardised reporting of suicide in Australia: rationale and program for change. Med J Aust. 2010;192:452-6.

28. Simon-Davies J. Suicide in Australia. Available from http://www.aph.gov.au/ About_Parliament/Parliamentary_Departments/Parliamentary_Library/pubs/ BN/2011-2012/Suicide. Canberra: Parliament of Australia, 2011.

29. Labonte R, Schrecker T. Globalization and social determinants of health: Introduction and methodological background (part 1 of 3). Global Health. 2007:3:5. doi:10.1186/1744-8603-3-5.

\section{Submit your next manuscript to BioMed Central and take full advantage of:}

- Convenient online submission

- Thorough peer review

- No space constraints or color figure charges

- Immediate publication on acceptance

- Inclusion in PubMed, CAS, Scopus and Google Scholar

- Research which is freely available for redistribution

Submit your manuscript at www.biomedcentral.com/submit 